\title{
Sustainable strategies towards a phosphorus circular economy
}

\author{
Thomas Nesme • Paul J. A. Withers
}

Received: 21 March 2016/ Accepted: 23 March 2016/Published online: 28 March 2016

(C) Springer Science+Business Media Dordrecht 2016

\section{Introduction}

Society as a whole uses too much phosphorus (P). This is putting unsustainable pressure on finite reserves of phosphate rock (PR), causing widespread eutrophication of inland and coastal water bodies, loss of terrestrial and aquatic ecosystem services and raising some concerns over the human health risks of high $\mathrm{P}$ in the diet (Elser and Bennett 2011; Withers et al. 2015b). Recent papers suggest that the upper tolerable limit, or planetary boundary of unacceptable consequence for humanity, for the key threat of freshwater eutrophication has already been exceeded (Carpenter and Bennett 2011; Steffen et al. 2015). Controversies arise over the scarcity of PR (Scholz 2013; Ulrich and Frossard 2014), but what is clear is that in the long term there is no other solution to these pressing environmental issues, but to develop a circular economy for $\mathrm{P}$, and close the $\mathrm{P}$ cycle through improved $\mathrm{P}$ recovery and recycling (Withers et al. 2015a).

T. Nesme $(\square)$

ISPA, Bordeaux Sciences Agro, INRA, 33175 Gradignan, France

e-mail: thomas.nesme@agro-bordeaux.fr

P. J. A. Withers

School of Environment, Natural Resources and

Geography, Bangor University, Bangor,

Gwynedd LL57 2UW, UK

e-mail: p.withers@bangor.ac.uk
However, P use efficiency in the current food chain remains very low with numerous surpluses, losses and poor recycling loops. This situation is exaggerated by clear imbalances of $\mathrm{P}$ use that exist across the globe with too little $\mathrm{P}$ used in poor countries, and too much $\mathrm{P}$ used in the richer countries, either in the past or currently (MacDonald et al. 2011). With a growing population demanding more food, bioenergy and clean water, and in relation to enhanced nitrogen $(\mathrm{N})$ supply to ecosystems and lower water availability, these imbalances in $\mathrm{P}$ use will become more critical (Jarvie et al. 2015; Peñuelas et al. 2013).

Resolving this societal problem requires sustainable solutions to improving $\mathrm{P}$ use efficiency along the whole food chain, and specifically within agricultural systems since farming is the main driver of the global $\mathrm{P}$ cycle. A range of sector and stakeholder perspectives on different aspects of the $\mathrm{P}$ cycle in different geographical regions were presented at the 4th Sustainable Phosphorus Summit held in Montpelier (France) in September 2014. In this conference special issue, we bring together a diversity of papers that focus on some approaches to developing more sustainable $\mathrm{P}$ use in agroecosystems. This special issue pays particular attention to papers that tackled integrated or largescale approaches: from plant to planet, from genotype to governance, from farm to waste management and those including losses to the environment. We also include a paper from our young scientists that clearly put into perspective the need for integrated approaches to resolve the $\mathrm{P}$ problem. 
Need for global but differentiated approaches: one size cannot fit all

While agriculture is the main driver of the modern $\mathrm{P}$ cycle, our analysis must go beyond pragmatic approaches that tackle agricultural $\mathrm{P}$ use efficiency and also consider those approaches that tackle the regulatory infrastructure. Such infrastructure is indeed needed to enact integrated practices to reduce environmental and human health threats and overcome issues of conflicting interests between stakeholder groups. Farmers are largely unaware of the consequences for PR consumption and global P inefficiency of the larger scale regional $P$ surpluses and imbalances that their farm P imports create (Metson et al. 2016; Nesme et al. 2016; Senthilkumar et al. 2012). Hence although they collectively decide on how much $\mathrm{P}$ is actually used, they have no control over the $\mathrm{P}$ imbalances generated at the larger scale. This situation has arisen because of a continuing lack of governance over P use globally, and a lack of infrastructure planning and integration between sectors and stakeholders in the food chain for improving $\mathrm{P}$ use efficiency regionally. Rosemarin et al. in this special issue provides a review of the key objectives, opportunities and metrics for P governance. They argue for a staged process that includes the establishment of a UN governance body that would oversee a 5-year rolling Global Phosphorus Facility for improving awareness, providing minimum standards and benchmarks for performance, guidance on best practice for improving $\mathrm{P}$ use efficiency along the food chain and suitable economic instruments to enact change. Such governance would help deliver a circular economy for P reliant on green principles, technologies and integrated strategies (Withers et al. 2015a, b) (Fig. 1).

However, the large imbalances in $\mathrm{P}$ stocks, flows and regulations across world countries call for global but differentiated actions on the $\mathrm{P}$ cycle. As highlighted by the 'Phosphorus trilemma' concept, interests and strategies differ between rich $\mathrm{P}$ consumers, poor $\mathrm{P}$ consumers and $\mathrm{P}$ fertiliser producers (Obersteiner et al. 2013). This diversity means that multiscale approaches are strongly needed as Shepherd et al. argue in their opinion paper resulting from a Young Scientist Workshop held during the conference. This diversity also means that one solution cannot fit all the different contexts, and that different but interconnected strategies should be investigated to limit $\mathrm{P}$ imbalances across the world (Fig. 1). We summarise in the next sections these key strategies drawn from the differentiated analysis of the $\mathrm{P}$ cycle.

\section{In rich nations: too much of a good thing}

Affluent countries mostly face excess of $\mathrm{P}$ that threatens freshwater quality. This excess is driven by intensive livestock industries and excessive past fertiliser use. Large research and extension efforts have been directed to limit $\mathrm{P}$ losses to water bodies and to $\mathrm{P}$ recovery and recycling from the large amounts of waste generated along the food chain. Even if regulations for $\mathrm{P}$ recovery and recycling remain in their infancy, national initiatives to limit $\mathrm{P}$ losses are more advanced. McDowell et al. in this special issue contrast the regulatory and voluntary approaches to reducing the eutrophication threat by farming in the USA, New Zealand and the UK. They conclude that scientific understanding of the processes and pathways of $\mathrm{P}$ transfer in catchments has still to be more effectively embedded in policy, and that social and economic barriers still exist to achieve lasting change and water quality improvements. In some areas, good water quality and sustainable intensification of agriculture may not be mutually achievable, requiring some prioritization of societal demands and change in land use (Doody et al. 2016).

In these rich nations, managing legacy $\mathrm{P}$ accumulated in soil, sediments and wastes is a major issue (Sattari et al. 2012). Rowe et al. in this special issue outline two key strategies to help utilise legacy $\mathrm{P}$ stores in soil and reduce reliance on highly soluble $\mathrm{P}$ fertilisers: Strategy A is simply to omit or reduce P inputs to rundown highly fertile soils (the largest eutrophication risk) to the agronomic optimum. This strategy gives most environmental gain with little or no detriment to agricultural production. Strategy B aims to further lower current critical soil fertility levels by adoption of innovative technologies, precision farming and a greater reliance on recovered $\mathrm{P}$ (termed agro-engineering), but further research is required to demonstrate this strategy is profitable (Withers et al. 2014). Vandamme et al (this issue) provide a timely example of the agro-engineering approach by exploring the feasibility of breeding more P-efficient rice varieties that require less $\mathrm{P}$. They recommend that genetic traits for improved $\mathrm{P}$ 
Fig. 1 The components of developing a circular economy for $\mathrm{P}$ to deliver multiple ecosystem services (green arrows), the main management strategies appropriate to rich, emerging and poor nations (red arrows) and the need for appropriate public and private regulations (blue arrows). (Color figure online)

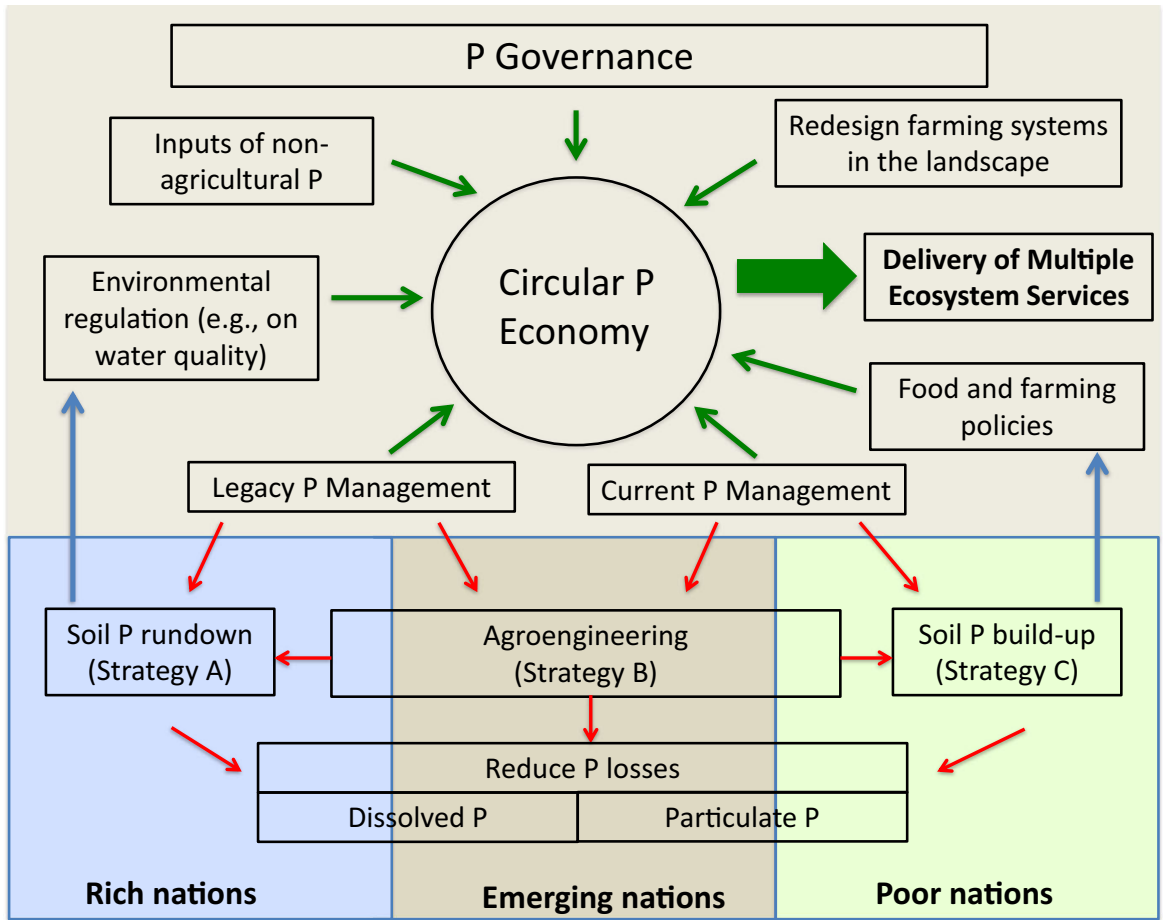

acquisition efficiency from soil, utilisation within the plant and low grain $\mathrm{P}$ accumulation could be incorporated into more P-efficient rice cultivars that can be tailored to specific (high P or low P) environments. Similar opportunities must exist for other grain crops.

In a country and countywide P budget, Hanserud et al. in this special issue conclude that there is enough $\mathrm{P}$ in livestock manures and sludge to theoretically fully meet all crop $\mathrm{P}$ needs in Norway, but the potential differed considerably between counties. Similar conclusions have been drawn from other regional studies in rich nations characterised by strong geographic and functional disconnection between arable and livestock production (Bateman et al. 2011; Metson et al. 2016; Nesme et al. 2015). Here, the transportability of bioresources remains a key technological and economic challenge to better close the $\mathrm{P}$ cycle and limit over-application of $\mathrm{P}$ fertilisers to agricultural soils.

Large legacy $\mathrm{P}$ stores, geographically separated livestock and arable production systems, intensive livestock systems and reliance on high fertiliser and feed $\mathrm{P}$ inputs make rich nations highly vulnerable to $\mathrm{P}$ losses to waterbodies. Such losses are very difficult to control because the sources and source areas are very variable, often unpredictable, and unlike point source wastewater discharges, there are many stakeholders that need to take action (Kleinman et al. 2015). Controlling soil erosion has received most attention because a large proportion of the $\mathrm{P}$ load delivered to waterbodies is in particulate form. These have not always been successful because the very measures required to reduce erosion vulnerability or retain $\mathrm{P}$ before entry to the waterbody can increase dissolved $P$ loss, which is much more bioavailable to aquatic biota (Ekholm and Krogerus 2003). Dodds and Sharpley in this special issue explore the potential conflicts that non-point source mitigation can lead to and conclude that dissolved and particulate $\mathrm{P}$ losses require separate strategies for their control. This is a major policy development for effective eutrophication control.

\section{In emerging nations: too little regulation of a good thing}

Emerging countries (e.g., BRICS) face a very rapidly evolving agriculture that has become heavily reliant on $\mathrm{P}$ fertilisers for growth: both livestock and arable farming systems are changing very quickly, often at a pace far greater than the one experienced by rich 
nations in their past (Bouwman et al. 2013; Cumming et al. 2014). Such dramatic changes are fuelled by recent increases in purchase power and related changes in food demand, in particular towards more meat-based diets (Bonhommeau et al. 2013; Tilman and Clark 2014). Many of those emerging nations are characterised by increasing disconnection between crops and livestock and by unparalleled use of mineral fertiliser often triggered by heavy subsidisation. However, farming systems are evolving faster than the set of environmental regulations required to manage the agricultural and urban wastes that they generate. This leads to great intensification of the $\mathrm{P}$ cycle (Liu et al. 2016) and dramatic consequences for $P$ losses to water bodies and for PR demand. Ma et al. in this special issue provide an integrated analysis of long-term changes (1950-2030) in the P cycle in China. They stress the strong intensification of this cycle during the past decades, fuelled by poorly regulated fertilisation practices and feed imports, which have led to major $\mathrm{P}$ losses to water-bodies and $\mathrm{P}$ accumulation in soils. They also demonstrate that, while increase in average purchase power (e.g., in terms of Gross Domestic Product, GDP) largely influenced $\mathrm{P}$ fertiliser use, losses and use-efficiency, many other factors interplay, leading to non-linear relationships between GDP and $\mathrm{P}$ flows in the food chain.

The high pace of agricultural transitions in these emerging nations raises major scientific questions about farming system assessment, planning and designing at different spatial scale (Fig. 1). Based on a thorough review of the effects of current and potentially improved practices in the fertiliser industry, agricultural production and wastewater management in terms of $\mathrm{P}$ use efficiency in food chains, $\mathrm{Li}$ et al. in this special issue propose a set of policy options and technical measures to make the $\mathrm{P}$ cycle more sustainable and circular in China. They concluded once again on the need for-and the potential benefits from-integrated approaches across sectors as well as barriers that have to be overcome. The need for this integration is mirrored across the richer nations (Withers et al. 2015b).

\section{In poor nations: not enough of a good thing}

Least advanced countries (e.g., many countries in SubSaharan Africa) face a critical deficit of $\mathrm{P}$ resource within agro-food chains: there is too little $\mathrm{P}$ in circulation in those countries that often have high $\mathrm{P}$ demanding soils due to high soil $\mathrm{P}$ fixation or very low total P content. Such P deficit limits crop and livestock production resulting in very little amounts of $\mathrm{P}$ in crop residues and animal manure to be recycled on agricultural soils (Cobo et al. 2010; Sanchez 2002; Smaling and Dixon 2006; Tittonell 2014; Zingore et al. 2007). In such context, there is little alternative but to increase inputs from mineral sources (Strategy C, Fig. 1). Nziguheba et al. in this special issue provide a broad review of $\mathrm{P}$ management issues and potential strategies to overcome $\mathrm{P}$ deficits in SubSaharan Africa. While they show that replenishing soil fertility is challenging due to high fertiliser costs and limited availability of organic $\mathrm{P}$ sources, they conclude on optimizing $\mathrm{P}$ use efficiency as the most plausible target pending increased accessibility of $\mathrm{P}$ sources to farmers. Research is strongly needed here to fill the gaps of knowledge about processes governing benefits associated with crop rotation, intercropping, P-efficient genotypes and residual $\mathrm{P}$ management (Ayaga et al. 2006). Involving smallholder farming communities is essential to deliver sustainable progress and preferable to the cavalier approach to landgrabbing by richer nations that is occurring in some regions (Byamugisha 2013).

\section{Future research directions}

This special issue has highlighted a number of research questions relating to both $\mathrm{PR}$ resource conservation and water quality protection. Several of these questions are related to critical segments of the $\mathrm{P}$ cycle (Fig. 2):

- Soil P stocks: legacy effects are likely to play a significant role to meet future crop P demand, especially in countries or regions that have accumulated $P$ in past decades. Key research questions are related to rhizosphere processes governing plant use of these often poorly available forms of soil P. Questions also arise over practices, indicators, decision-tools and regulations that can help to better account for legacy $\mathrm{P}$ in farming system design operations.

- Losses to water bodies: although individual mechanisms and mitigation options are well known, 


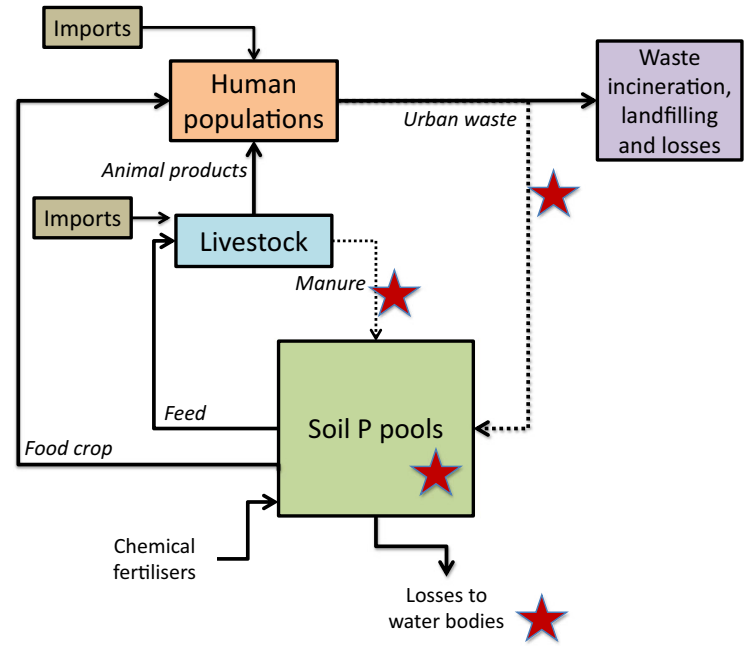

Fig. 2 The $\mathrm{P}$ cycle in social-ecological systems. Recycling loops are represented in dotted arrows. Scientific questions related to the critical segments of the $\mathrm{P}$ cycle are indicated by red stars. (Color figure online)

integrated approaches that combine long-term and multi-criteria assessment still have to be developed, including more effective implementation on the ground. Urgent research projects are also needed to understand whether public policies efficiently target these losses and to better support sound policies about landscape and agricultural planning.

- Recycling from urban and agricultural waste: organic wastes $\mathrm{P}$ are likely to play an increasing role in supplying $\mathrm{P}$ to agricultural soils in the future. This is especially true within circular economy frameworks that emerge in numerous places. Extensive engineering efforts are also required to better extract $\mathrm{P}$ from waste under innovative mineral forms (such as struvite and calcium phosphates). However, key questions remain over the ability of these recycled $\mathrm{P}$ sources to meet crop $\mathrm{P}$ demand. In particular, it is still unclear how recycled $\mathrm{P}$ products compare to mineral $\mathrm{P}$ sources, and how technology can help improve their plant availability. Numerous questions also exist about the barriers toward increased recycling that potentially exist and how to overcome these barriers within new planning policies.

Beyond these critical segments of the $\mathrm{P}$ cycle, integrated approaches in plant, farming systems, landscape and food chain design are strongly required.
Although we have made some progress in understanding the different segments of the P cycle (van Dijk et al. 2016), and in proposing some intervention techniques (Schoumans et al. 2015), there is now a need to better integrate this progress. Up-scaling scenarios into system-based assessments incorporating combinations of different techniques, regulations and driving forces are particularly needed to assess consequences for global $\mathrm{P}$ resources. Keywords here are interactions, feedbacks, behaviour changes and rebound effects. In that sense, we need a stronger economic argument to justify a transition to a circular P economy (Lederer et al. 2014). Such integration objectives should not, however, be at the expense of continuous progress on some specific, critical segments of the $\mathrm{P}$ cycle as highlighted above.

Finally, we need to understand the wider role of $\mathrm{P}$ in delivering multiple ecosystem services and not just in relation to food and bioenergy production and water quality. Due to the critical role played by $\mathrm{P}$ in governing multiple ecosystem processes (e.g., primary productivity, nutrient cycling in soils, water eutrophication) and related ecosystem services (e.g., food and fuel delivery, carbon sequestration, clean water provisioning, fishing) along the land-water continuum, multi-criteria approaches are urgently needed. Prioritisation of those ecosystem services valued by society will govern trade-offs-and selection of win-win scenarios-between the need to increase food and bioenergy and provide safe clean water (Jarvie et al. 2015).

We hope the set of papers selected in this special issue will illustrate some of these research priorities and will foster future scientific discussion within the $\mathrm{P}$ community.

\section{References}

Ayaga G, Todd A, Brookes PC (2006) Enhanced biological cycling of phosphorus increases its availability to crops in low-input sub-Saharan farming systems. Soil Biol Biochem 38:81-90

Bateman A, van der Horst D, Boardman D, Kansal A, CarliellMarquet C (2011) Closing the phosphorus loop in England: the spatio-temporal balance of phosphorus capture from manure versus crop demand for fertiliser. Resour Conserv Recycl 55:1146-1153

Bonhommeau S, Dubroca L, Le Pape O, Barden J, Kaplan DM, Chassot E, Nieblas AE (2013) Eating up the world's food 
web and the human trophic level. Proc Natl Acad Sci USA 110:20617-20620. http://www.pnas.org/cgi/doi/10.1073/ pnas. 1305827110

Bouwman AF et al (2013) Exploring global changes in nitrogen and phosphorus cycles in agriculture induced by livestock production over the 1900-2050 period. Proc Natl Acad Sci USA 110:20882-20887. http://dx.doi.org/10.1073/pnas. 1012878108

Byamugisha FFK (2013) Securing Africa's land for sahred prosperity. World Bank, Washington

Carpenter SR, Bennett EM (2011) Reconsideration of the planetary boundary for phosphorus. Environ Res Lett 6:014009. doi:10.1088/1748-9326/6/1/014009

Cobo JG, Dercon G, Cadisch G (2010) Nutrient balances in African land use systems across different spatial scales: a review of approaches, challenges and progress. Agric Ecosyst Environ 136:1-15

Cumming GS, Buerkert A, Hoffmann EM, Schlecht E, von Cramon-Taubadel S, Tscharntke T (2014) Implications of agricultural transitions and urbanization for ecosystem services. Nature 515:50-57. doi:10.1038/nature13945

Doody DG et al (2016) Optimising land use for the delivery of catchment ecosystem services. Front Ecol Environ (in press)

Ekholm P, Krogerus K (2003) Determining algal-available phosphorus of differing origin: routine phosphorus analyses versus algal assays. Hydrobiologia 492:29-42

Elser J, Bennett EM (2011) A broken biogeochemical cycle. Nature 478:29-31

Jarvie HP, Sharpley AN, Flaten D, Kleinman PJA, Jenkins A, Simmons T (2015) The pivotal role of phosphorus in a resilient water-energy-food security nexus. J Environ Qual 44:1049-1062

Kleinman PJA, Sharpley AN, Withers PJA, Bergstrom L, Johnson LT, Doody DG (2015) Implementing agricultural phosphorus science and management to combat eutrophication. AMBIO 44(2):S297-S310

Lederer J, Laner D, Fellner J (2014) A framework for the evaluation of anthropogenic resources: the case study of phosphorus stocks in Austria. J Clean Prod 84:368-381

Liu X, Sheng H, Jiang S, Yuan Z, Zhang C, Elser JJ (2016) Intensification of phosphorus cycling in China since the 1600 s. Proc Natl Acad Sci USA 113:2609-2614. http:// www.pnas.org/cgi/doi/10.1073/pnas.1519554113

MacDonald GK, Bennett EM, Potter PA, Ramankutty N (2011) Agronomic phosphorus imbalances across the world's croplands. Proc Natl Acad Sci USA 108:3086-3091

Metson GS, MacDonald GK, Haberman D, Nesme T, Bennett EM (2016) Feeding the corn belt: opportunities for phosphorus recycling in US agriculture. Sci Total Environ 542:1117-1126

Nesme T, Senthilkumar K, Mollier A, Pellerin S (2015) Effects of crop and livestock segregation on phosphorus resource use: a systematic, regional analysis. Eur J Agron 71:88-95. doi:10.1016/j.eja.2015.08.001

Nesme T, Roques S, Metson GS, Bennett EM (2016) The surprisingly small but increasing role of international agricultural trade on the European Union's dependence on mineral phosphorus fertiliser. Environ Res Lett 11:025003. doi:10.1088/1748-9326/11/2/025003

Obersteiner M, Peñuelas J, Ciais P, van der Velde M, Janssens IA (2013) The phosphorus trilemma. Nat Geosci 6:897-898

Peñuelas J et al (2013) Human-induced nitrogen-phosphorus imbalances alter natural and managed ecosystems across the globe. Nat Commun 4:2934. doi:10.1038/ncomms3934

Sanchez PA (2002) Soil fertility and hunger in Africa. Science 295:2019-2020

Sattari SZ, Bouwman AF, Giller KE, Van Ittersum MK (2012) Residual soil phosphorus as the missing piece in the global phosphorus crisis puzzle. Proc Natl Acad Sci USA 109:6348-6353

Scholz RW (2013) Approaching a dynamic view on the availability of mineral resources: what we may learn from the case of phosphorus? Glob Environ Change 23:11-27. doi:10.1016/j.gloenvcha.2012.10.013

Schoumans OF, Bouraoui F, Kabbe C, Oenema O, van Dijk KC (2015) Phosphorus management in Europe in a changing world. Ambio 44:180-192

Senthilkumar K, Nesme T, Mollier A, Pellerin S (2012) Regional-scale phosphorus flows and budgets within France: the importance of agricultural production systems. Nutr Cycl Agroecosys 92:225-236

Smaling EMA, Dixon J (2006) Adding a soil fertility dimension to the global farming systems approach, with cases from Africa. Agric Ecosyst Environ 116:15-26

Steffen W et al (2015) Planetary boundaries: guiding human development on a changing planet. Science 347:1259855. doi:10.1126/science.1259855

Tilman D, Clark M (2014) Global diets link environmental sustainability and human health. Nature 515:518-522. http://www.nature.com/doifinder/10.1038/nature13959

Tittonell P (2014) Livelihood strategies, resilience and transformability in African agroecosystems. Agric Syst 126:3-14. doi:10.1016/j.agsy.2013.10.010

Ulrich AE, Frossard E (2014) On the history of a reoccurring concept: phosphorus scarcity. Sci Total Environ 490:694-707

van Dijk KC, Lesschen JP, Oenema O (2016) Phosphorus flows and balances of the European Union Member States. Sci Total Environ 542:1078-1093

Withers PJA, Sylvester-Bradley R, Jones DL, Healey JR, Talboys PJ (2014) Feed the crop not the soil: rethinking phosphorus management in the food chain. Environ Sci Technol 48:6523-6530

Withers PJA, Elser JJ, Hilton J, Ohtake H, Schipper W, van Dijk KC (2015a) Greening the global phosphorus cycle: how green chemistry can help achieve planetary P sustainability. Green Chem 17:2087

Withers PJA et al (2015b) Stewardship to tackle global phosphorus inefficiency: the case of Europe. Ambio 44:S193S206. doi:10.1007/s13280-014-0614-8

Zingore S, Murwira HK, Delve RJ, Giller KE (2007) Soil type, management history and current resource allocation: three dimensions regulating variability in crop productivity on African smallholder farms. Field Crop Res 101:296-305 